\title{
Monitoring of abusers by clinical laboratory tests and eye pupil examinations
}

\author{
Majid Rezaei Basiri ${ }^{1-3 *}$, Saleh Alilou ${ }^{3}$ and Darya Alilou ${ }^{3}$ \\ ${ }^{1}$ Department of Pharmacology And Toxicology, School of Pharmacy, Tabriz University of Medical Sciences, Tabriz, Iran \\ ${ }^{2}$ Medical Education Research Center, Tabriz University of Medical Sciences, Tabriz, Iran \\ ${ }^{3}$ Welfare Organization of East Azarbayjan, Tabriz, Iran
}

\begin{abstract}
In this study $(\mathrm{n}=500)$ fresh blood and urine samples of male abusers were recruited to distinguish abuse drugs and some treatment drugs. All the study population were male, and their age range was mean $\pm \mathrm{SD}=41 \pm 21$. They had often history consumption of the abuse drugs and take other medication too. All data were collected and analyzed by one-way ANOVA and t-test before and after detoxification. The rapid strip methods and their eye pupils' variations determined abusers 'treatment conditions. When comparing the test results p-value: $0 \leq 0.05$ was considered as significance level. Treatment duration follow-up of all abuser's urine samples indicated negative results. According to the findings of this investigation rapid strip tests were useful in urine samples and eye pupils' variations were accessible confirmation method.
\end{abstract}

\section{Introduction}

Nowadays, addiction epidemic has changed to serious social challenge and problem even in developed societies. In the poor countries social damages are consequences increased between abusers population. Statistical studies and appropriate treatment and distinguish methods will be highly efficient in preventive of addicted population. Scientific progress and advent of new sciences have led to production of new kinetic abuse substances in industrial communities. This is while during recent decade's addiction epidemics used to involved traditional substances such as opium. Different studies have been conducted in western and weak countries in line with diagnosis, treatment and prevention of traditional and industrial abuse drugs. So, they are currently conducted now. It seems that rapid and cheap-effective methods are important in addiction control and inhibition process. Based on new studies, use of fresh biologic sample of the abusers has been proposed. Hence, recruitment of the abovementioned methods especially in developing and highly populated countries will be cost effective. Use of advanced experimental tools is essential in addictives and abuse drugs distinguish, however they are not economically available all the times. Hence and according to what was mentioned earlier we propose use of initial facilities such as Immuno-chromatography rapid strips as effective in urine samples and experimental tools such evaluation of eye pupils' variations and then we develop the research procedure and framework based on them [1-10].

\section{Methods and materials}

In this study a number of 500 male abusers who had addictive substances and drugs abuse such as opium, heroin, methadone, cannabis, methamphetamine, were selected and above-mentioned substances abuse form along with research participation consent form were filled for them. Each abuser subject was asked to give a fresh sample of his urine to the laboratory before detoxification. Samples were collected to do the tests. The urine were tested by rapid strips after adding some droplets of amoniaque solution, sensitivity of which is $300 \mathrm{Ng} / \mathrm{ml}$ to abuse drugs and then the results were recorded. In this study, all of the urine samples of abusers who were detoxified without using drug were tested after improvement using above-mentioned method and the results were recorded after treatment. Moreover, before detoxification confirmation of abusing and their eye pupil variation results were recorded, too. In this research, all male abusers who participated in the study gave about $100^{c c}$ urine sample to the laboratory for being tested before and after treatment. The use some droplets of amoniaque solution in urine $f$ abusers before their test significantly remove false negative results. All of the abusers had smoking, alcohol, pain-relief and sedative medicines history [1-12]. Majority of the abusers had relatively long history of using addictive substances or drugs for more than five years. Some biochemical tests such as liver enzymes experiments were conducted on the blood samples of the study population and then their results were recorded. Moreover, some studies were also carried out to investigate anemia level of the abusers. Results of all above-mentioned tests have been shown in results the tables [10-19].

\section{Results}

In this research all data were obtained from questioners and related tests results. Table 1 Shows number of some of the Consumption history with tested between the study populations. As it can be seen in the table use of abuse substances such as

${ }^{\star}$ Correspondence to: Majid Rezaei Basiri, Department of Toxicology, Soleyman khater Avenue - Tabriz welfare organization of East Azarbayjan, Tabriz, Iran, Tel: +98 9354235863; Email: basiri@alumnus.tums.ac.ir

Key words: abusers, urine sample, rapid strip tests, detoxification, myosis, mydriasis

Received: December 03, 2019; Accepted: December 20, 2019; Published: December 23, 2019 
heroin, opium and cannabis drugs is becoming prevalent. Table 2 shows number of positive and negative results of prevalence of abuse substances (e.g. Heroin, opium and methamphetamine, cannabis drugs...) based on the addicts age and use history before detoxification and after treatment among urine samples and according to the rapid strip tests. Table 3 shows check of eye pupils variations in some the abusers. Table 4 shows negative results confirmatory through application of rapid strip tests above 35 years old abusers. In this study after data collection, results were compared before and after detoxification periods and then one way ANOVA and t-test statistical analyses were conducted on the data and finally $\mathrm{p} \leq 0.05$ was considered as significant for all statistical population $[1-5,8]$.

\section{Discussion}

Abusers who consumed narcotic and motivation abuse drugs in this study. They had often history consumption of the other following drugs abuse such: Heroin-Morphine-Codeine-Cannabis-MethadoneTramadol-Buprexin-Methamphetamine- cocaine.... too. Also they had used other medication such: BNZ, TCA, MAO, Vitamins, Minerals, Anti hyperlipidemia and anti-hypertension and antipsychotic drugs, anti-cancer... supervision of clinics physicians. The rout of abuse drugs consumption between of abusers were often oral and sniffing but some of them had injected situation. In this study constriction (Myosis) and dilation (Mydriasis) of eye pupils of abusers were checked through

Table 1. Shows number of some of the consumption history with tested between the study populations

\begin{tabular}{|c|c|c|c|c|}
\hline & \multirow{2}{*}{ Drug names } & \multirow{2}{*}{ Men } & Consumption & \multirow{2}{*}{ Abuser numbers } \\
\hline & & & History & \\
\hline \multirow{2}{*}{ No } & \multirow{2}{*}{ Abuse drugs } & Ages Mean & \multirow{2}{*}{ month or year } & \multirow{2}{*}{$\mathrm{N}$} \\
\hline & & Mean \pm SD & & \\
\hline 1 & Herion & 52 & $3 \mathrm{yrs}$ & $\mathrm{N}=500$ \\
\hline 2 & Metamphetamine & 42 & $2 \mathrm{yrs}$ & $\mathrm{N}=500$ \\
\hline 3 & Opium & 42 & $4 \mathrm{yrs}$ & $\mathrm{N}=500$ \\
\hline 4 & Methadone & 41 & $3 \mathrm{yrs}$ & $\mathrm{N}=500$ \\
\hline 5 & THC & 43 & $2 \mathrm{yrs}$ & $\mathrm{N}=500$ \\
\hline 6 & Bupernorphine & 31 & $2 \mathrm{yrs}$ & $\mathrm{N}=500$ \\
\hline 7 & Codein & 61 & 3 yrs & $\mathrm{N}=500$ \\
\hline 8 & $\mathrm{BNZ}$ & 57 & $3 \mathrm{yrs}$ & $\mathrm{N}=500$ \\
\hline 9 & TCA & 33 & $2 \mathrm{yrs}$ & $\mathrm{N}=500$ \\
\hline 10 & BAR & 35 & $1 \mathrm{yrs}$ & $\mathrm{N}=500$ \\
\hline 11 & Cocaine & 36 & $1 \mathrm{yrs}$ & $\mathrm{N}=500$ \\
\hline 12 & TML & 50 & $2 \mathrm{yrs}$ & $\mathrm{N}=500$ \\
\hline
\end{tabular}

Ages mean >30, N=500, BNZ: Bezodiazepines, TCA: Three Cyclic Antidepressants, BAR: Barbiturates, Meta: Metamphetamine, TML: Tramadol

Table 2. Urine rapid strip test results during the period of before and after detoxification in population study of men groups

\begin{tabular}{|c|c|c|c|c|c|}
\hline & Age & Consumption & Consumption & Before detoxification & After detoxification \\
\hline No & & & year & $>300 \mathrm{ng} / \mathrm{ml}$ & $<300 \mathrm{ng} / \mathrm{ml}$ \\
\hline 1 & 61 & Mor & $21 \mathrm{yrs}$ & + & - \\
\hline 2 & 57 & Metha & $25 \mathrm{yrs}$ & + & - \\
\hline 3 & 56 & Mor & $22 \mathrm{yrs}$ & + & - \\
\hline 4 & 59 & Mor & $23 \mathrm{yrs}$ & + & - \\
\hline 5 & 54 & Metha & $25 \mathrm{yrs}$ & + & - \\
\hline 6 & 51 & Metha & $18 \mathrm{yrs}$ & + & - \\
\hline 7 & 48 & Mor & $17 \mathrm{yrs}$ & + & - \\
\hline 8 & 45 & Mor & $15 \mathrm{yrs}$ & + & - \\
\hline 9 & 42 & Meta & $16 \mathrm{yrs}$ & + & - \\
\hline 10 & 45 & Mor & $25 \mathrm{yrs}$ & + & - \\
\hline 11 & 41 & Mor & 18 yrs & + & - \\
\hline 12 & 40 & Meta & $14 \mathrm{yrs}$ & + & - \\
\hline 13 & 59 & Mor & 13 yrs & + & - \\
\hline 14 & 43 & Mor & $10 \mathrm{yrs}$ & + & - \\
\hline 15 & 38 & Mor & $11 \mathrm{yrs}$ & + & - \\
\hline 16 & 33 & Meta & $6 \mathrm{yrs}$ & + & - \\
\hline 17 & 32 & THC & 8 yrs & + & - \\
\hline 18 & 34 & Meta & $15 \mathrm{yrs}$ & + & - \\
\hline 19 & 38 & THC & $20 \mathrm{yrs}$ & + & - \\
\hline 20 & 31 & Mor & $18 \mathrm{yrs}$ & + & - \\
\hline 21 & 36 & Meta & $14 \mathrm{yrs}$ & + & - \\
\hline 22 & 31 & Meta & $6 \mathrm{yrs}$ & + & - \\
\hline 23 & 46 & THC & $4 \mathrm{yrs}$ & + & - \\
\hline 24 & 44 & Mor & $6 \mathrm{yrs}$ & + & - \\
\hline 25 & 44 & Mor & $23 \mathrm{yrs}$ & + & - \\
\hline 26 & 43 & Metha & $21 \mathrm{yrs}$ & + & - \\
\hline 27 & 59 & Mor & $25 \mathrm{yrs}$ & + & - \\
\hline
\end{tabular}




\begin{tabular}{|l|l|l|l|l|l|}
\hline 28 & 30 & Metha & $13 \mathrm{yrs}$ & + & + \\
\hline 29 & 33 & Meta & $10 \mathrm{yrs}$ & + & - \\
\hline 30 & 31 & Meta & $9 \mathrm{yrs}$ & + & - \\
\hline 31 & 30 & THC & $6 \mathrm{yrs}$ & + & - \\
\hline 32 & 59 & Metha & $25 \mathrm{yrs}$ & - \\
\hline 33 & 49 & Metha & $21 \mathrm{yrs}$ & - \\
\hline 34 & 59 & Metha & $29 \mathrm{yrs}$ & + \\
\hline 35 & 40 & Mor & $17 \mathrm{yrs}$ & - \\
\hline
\end{tabular}

$>300 \mathrm{ng} / \mathrm{ml}$ : positive results (+), $<300 \mathrm{ng} / \mathrm{ml}$ : Negative results (-) N=500, Rapid strip test, Abuser drugs (MA, Methadon, THC: Canabinoid, opioums). Meta: Metamphetamine, Mor: Morphine (Opium or Heroin) detection in men abusers Urine samples. Anowa one way, $\mathrm{p}=0.001$

Table 3. Shows check of eye pupils variations in the some abusers of study group

\begin{tabular}{|c|c|c|c|c|c|}
\hline & Men & Consumption & $\begin{array}{c}\text { Urine rapid strip } \\
\text { tests results }\end{array}$ & Myosis & Mydriasis \\
\hline No & Age & & $>300 \mathrm{ng} / \mathrm{ml}$ & & \\
\hline 1 & 60 & Opium & + & + & - \\
\hline 2 & 46 & Heroin & + & + & - \\
\hline 3 & 45 & Methdone & + & + & - \\
\hline 4 & 41 & Metamphetamine & + & - & + \\
\hline 5 & 39 & Methdone+Meta & + & - & \pm \\
\hline 6 & 30 & Morphine + Meta & + & - & \pm \\
\hline 7 & 37 & Morphine + Meta + Methadone & + & \pm & - \\
\hline 8 & 38 & BNZ+Morph+Meta & + & \pm & - \\
\hline 9 & 32 & TCA+Meta+Methadone & + & - & \pm \\
\hline 10 & 30 & TCA+Morph+Meta & + & - & \pm \\
\hline 11 & 31 & Morph+Methadone+BNZ & + & + & - \\
\hline 12 & 36 & TCA+Metamphetamine & + & - & + \\
\hline 13 & 39 & Opium + Heroin + Methadone & + & . & - \\
\hline 14 & 40 & Opium+Heroin+TCA & + & \pm & - \\
\hline 15 & 42 & Opium+Heroin + Meta & + & \pm & - \\
\hline
\end{tabular}

t: Mild myosis or mydrisis, pupils check, urine rapid strip tets, Meta: Metamphetamine; Morphine(Opium or Heroin; BNZ:Benzodiazepine; TCA: Three cyclic Antidepressants.

Table 4. Urine test results have shown after detoxification process of some cases

\begin{tabular}{|c|c|c|c|c|}
\hline & \multirow{2}{*}{ Consumption } & \multirow{2}{*}{ Men } & Consumption & \multirow{2}{*}{$\begin{array}{l}\text { Urine rapid strip } \\
\text { tests results }\end{array}$} \\
\hline & & & history & \\
\hline No & & Age & year & $<300 \mathrm{ng} / \mathrm{ml}$ \\
\hline 1 & Metha & 54 & $5 \mathrm{yr}$ & - \\
\hline 2 & Metha & 47 & $4 \mathrm{yr}$ & - \\
\hline 3 & Mor & 43 & $2 \mathrm{yr}$ & - \\
\hline 4 & Mor & 42 & $1 \mathrm{yr}$ & - \\
\hline 5 & Meta & 40 & $2 \mathrm{yr}$ & - \\
\hline 6 & Meta & 31 & $1 \mathrm{yr}$ & - \\
\hline 7 & Metha & 61 & $10 \mathrm{yr}$ & - \\
\hline 8 & Metha & 60 & $20 \mathrm{yr}$ & - \\
\hline 9 & Mor & 31 & $1 \mathrm{yr}$ & - \\
\hline 10 & Metha & 32 & $2 \mathrm{yr}$ & - \\
\hline 11 & Metha & 34 & $2 \mathrm{yr}$ & - \\
\hline \multirow[t]{2}{*}{12} & THC & 59 & $3 y r$ & - \\
\hline & Meta & & & \\
\hline
\end{tabular}

Age $>30, \mathrm{~N}=12$, Negative results have after detoxification through Urine rapid strip tests results. $(+),<300 \mathrm{ng} / \mathrm{ml}$ : Negative results (-), Rapid strip test, Abuser drugs (MA:Methadon, THC: Canabinoid, opioums). Meta: Metamphetamine, Mor: Morphine (Opium or Heroin) detection in men abusers Urine.

clinics physicians. Table 4 detail shows check of eye pupils of abusers after their drug abuse consumption. Also, normal position of eye pupils and negative results of urine rapid test were significantly reported after detoxification of abusers in this study. Also, in some cases who denied their abuse drug consumption with infusion of some unite of naloxone they were withdrew supervision of clinics physicians. In this study other parameters of clinical biochemistry such liver function tests of abusers and their liver enzymes were evaluated too. $[1-3,8-19]$

\section{Conclusions}

We conclude that between all drug analytical methods the cheapest and easiest tests of abuse drugs in urine samples is accesible test to distinguishing, the base function of Rapid strip test kits is Immunochromatography. They are made and available cheaper than other methods in clinical laboratory. According to background of this study, we will be recommended that to detection and diagnosis of other medicinal or drugs poisoning rapid strip test kits with sensitivity 
above $300 \mathrm{ng} / \mathrm{mL}$ are usefulness. Also, other physical examination of physicians are requirement.

\section{Acknowledgment}

We acknowledge that all abuser patients to participation of them in this study. we have special thanks of from all clinics that supervion of welfare organization. We are grateful from Tabriz/Iran welfare organization to financial support of this study.

\section{References}

1. Cone EJ, Dickerson S (1992) Forensic drug testing for opiates. IV. Analytica sensitivity, specificity, and accuracy of commercial urine opiate immunoassays. J Anal Toxicol 16: 72-78. [Crossref]

2. Rezai-Basiri M, Ghazi-Khansari M, Faghih A, Sadeghi M, Lotfalizadeh N, et al. (2010) Screening of morphine and codeine in urine of opioid abusers by rapid and TLC analysis. Eur J Gen Med 7: 192-196.

3. Pergolizzi J, Pappagallo M, Stauffer J, Gharibo C, Fortner N, et al. (2010) The role of urine drug testing for patients on opioid therapy. Pain Pract 10: 497-507. [Crossref]

4. Rezaei-Basiri M, Rezazadeh H, Asvadi-Kermani I, Davoodi A, Eghbal MA, et al. (2014) Antimutagenic effects of vitamin E on oncology and non oncology hospital nurses by comet assay. Drug Res 64: 337-342.

5. Majid RB, Rezazadeh H, Asvadi-Kermani I, Ghazi-Khansari M, Golchin M, et al (2013) Effect of vitamin e on uroepithelial cells and changes of urinary sediments in oncology hospital nursing personnel. J Clin Diagn Res 7: 2570-2572. [Crossref]

6. Drummer OH, Odell M (2001) Forensic pharmacology of drugs of abuse. FBI Publications: 1528.

7. Grönholm M, Lillsunde P (2001) A comparison between on-site immunoassay drugtesting devices and laboratory results. Foren Sci Intern 121: 37-46.
8. Pragst F, Balikova MA (2006) State of the art in hair analysis for detection of drug and alcohol abuse. Clin Chim Acta 370: 17-49. [Crossref]

9. Verstraete AG (2004) Detection times of drugs of abuse in blood, urine, and oral fluid. Ther Drug Monit 26: 200-205. [Crossref]

10. Majid Rezaei Basiri (2019) Evaluation of abuse drugs tests variations in fresh biological samples of abusers. J Addic Ther 6: 33 .

11. Dettmeyer R, Friedrich K, Schmidt P, Madea B (2009) Heroin-asso- ciated myocardial damages--conventional and immunohis- tochemical investigations. Forensic Sci Int 187: 42-46. [Crossref]

12. Baj J, Radzikowska E, Maciejewski M, Dąbrowski A, Torres K (2017) Prediction of acute pancreatitis in the earliest stages - role of biochemical parameters and histopathological changes. Pol Przegl Chir 89: 31-38. [Croddref]

13. Bosker WM, Huestis MA (2009) Oral fluid testing for drugs of abuse. Clin Chem 55: 1910-1931. [Crossref]

14. Hackett LP, Dusci LJ, Ilett KF (2002) Optimizing the hydrolysis of codeine and morphine glucuronides in urine. Ther Drug Monit 24: 652-657.

15. Wille SM, Raes E, Lillsunde P, Gunnar T, Laloup M, et al. (2009) Relationship between oral fluid and blood concentrations of drugs of abuse in drivers suspected of driving under the influence of drugs. Ther Drug Monit 31: 511-519.

16. Moeller KE, Lee KC, Kissack JC (2008) Urine drug screening: Practical guide for clinicians. Mayo Clin Proc 83: 66-76. [Crossref]

17. Helmut W (1994) Pupil examination and evaluation of pupillary disorders. NeuroOphthalmology 14: 283-295.

18. Tennant F (1988) The rapid eye test to detect drug abuse. Postgrad Med 84:108-114

19. Shinar D, Schechtman E (2005) Drug identification performance on the basis of observable signs and symptoms. Accid Anal Prev 37: 843-851. [Crossref]

Copyright: $(02019$ Basiri MR. This is an open-access article distributed under the terms of the Creative Commons Attribution License, which permits unrestricted use, distribution, and reproduction in any medium, provided the original author and source are credited. 